\title{
Sensitivity of Quasi-Stationary Band-Shaped Precipitation System to Topography: A Case Study for 28 August 2008 Okazaki Heavy Rainfall Event
}

\author{
Yoshinori TAKASAKI \\ Graduate School of Geo-Environmental Sciences, Rissho University, Kumagaya, Japan \\ Masanori YOSHIZAKI, Asuka SUZUKI-PARKER, and Yasushi WATARAI \\ Faculty of Geo-Environmental Sciences, Rissho University, Kumagaya, Japan
}

(Manuscript received 27 July 2017, in final form 11 December 2018)

\begin{abstract}
The Okazaki heavy rainfall event, which occurred at midnight on 28 August 2008 around Okazaki city, Japan, was produced by a quasi-stationary, band-shaped precipitation system. It remained quasi-stationary for approximately five hours over Okazaki city and the surrounding area, producing prolonged, heavy precipitation. This study presents sensitivity numerical experiments to examine the surrounding mountainous topography's effect on the precipitation system using the Weather Research and Forecasting (WRF) model with $500 \mathrm{~m}$ horizontal resolution. In an experiment without the mountains to the east of Okazaki city, the quasi-stationary precipitation system was not reproduced. On the other hand, experiments including the eastern mountains produced a low-level convergence south of Okazaki city, resulting in a quasi-stationary precipitation system with prolonged precipitation, as observed near Okazaki city. The convergence was formed by sustained easterly and northerly winds blowing in western Okazaki city. The easterlies were maintained by a westward shift of southeasterly inflow from the Pacific Ocean due to the enhanced pressure gradient on the upstream side of the eastern mountains in the low-level atmosphere with low Froude numbers $(F r<0.5)$. The easterlies also steadily supplied warm and moist air to the quasi-stationary system, leading to prolonged heavy precipitation.
\end{abstract}

Keywords band-shaped precipitation system; mountains; Okazaki heavy rainfall event

Citation Takasaki, Y., M. Yoshizaki, A. Suzuki-Parker, and Y. Watarai, 2019: Sensitivity of quasi-stationary bandshaped precipitation system to topography: A case study for 28 August 2008 Okazaki heavy rainfall event. J. Meteor. Soc. Japan, 97, 453-466, doi:10.2151/jmsj.2019-026.

\section{Introduction}

Many heavy rainfall events consist of band-shaped precipitation systems (Bluestein and Jain 1985; Ogura 1991, 2015). As has been indicated by past studies, topography is considered a contributing factor to forming band-shaped precipitation. In a classic work

Corresponding author: Yoshinori Takasaki, Graduate School of Geo-Environmental Sciences, Rissho University, 1700 Magechi, Kumagaya, 360-0194, Japan

E-mail: 139w00001@rissho-univ.jp

J-stage Advance Published Date: 24 December 2018 by Houze (1993), heavy rainfall events are classified according to their relationships with topography. A more recent work by Lin (2007) provides a summary of mountainous topography effects at various scales on precipitation around the world. In Japan, associations between heavy rainfall events and local topography have been reported in a number of case studies (Ogura et al. 1985; Kanada et al. 2000; Yoshizaki et al. 2000; Watanabe 2008; Ninomiya 2011; Morotomi et al. 2012). Numerical experiments with modified topography have shown that mountainous topography affects precipitation intensity but has little impact on 
spatial distribution (Suzuki et al. 2008; Kurihara et al. 2009; Tsuguti and Seino 2017: Meteorological Research Institute 2017). A similar finding was made for a heavy rainfall event in Texas (Nielsen et al. 2016). However, there are limited numerical experiments with modified topography. Furthermore, not all heavy rainfall events are affected by topography (e.g., Kato and Goda 2001). To develop a comprehensive understanding of the precipitation-topography relationship for local heavy rainfall events, it is important to accumulate more cases with various topography and atmospheric conditions.

Heavy rainfall events occurred over several areas in Japan during 26-31 August 2008. Ogura et al. (2011) showed that most of events during this period could be classified into two types. The first type is an organized, band-shaped, mesoscale convective system (MCS) along an upper-level moisture front, and the second is a back-building type system in which MCS forms windward direction into an organized, bandshaped precipitation system (Bluestein and Jain 1985; Kato 1998). Among these, a heavy rainfall event, reaching an hourly precipitation amount of $146.5 \mathrm{~mm}$ (the Okazaki heavy rainfall event), occurred at 1500 UTC and lasted until 2000 UTC around Okazaki, a city in central Japan (Fig. 1). Development of the Okazaki heavy rainfall event can be divided into two stages; in stage 1 (1300-1600 UTC), the precipitation system moved southeastward, and in stage 2 (1700 UTC and later) it became quasi-stationary around Okazaki city (details shown in Section 2).

Shinoda et al. (2009) examined stage 1 of the Okazaki heavy rainfall event using X-band, polarimetric Doppler radar observations, and numerical simulations. They showed that this event was associated with a band-shaped precipitation system with a back-and side-building type structure (Seko 2001), which is maintained by mid-level winds and lower inflows blowing from different directions. However, as Shinoda et al. (2009) focused on stage 1 of the Okazaki event, the potential mechanism behind the quasi-stationary precipitation system during stage 2 is still unknown.

Recognizing the mountainous topography around Okazaki city, the present study examines the topography's effect on the maintenance of the quasi-stationary band-shaped precipitation system during stage 2 of the Okazaki heavy rainfall event. Section 2 of this paper analyzes synoptic fields and mesoscale features of precipitation in the Okazaki heavy rainfall event. Section 3 outlines the numerical model used in this study. Section 4 describes the precipitation system's characteristics simulated by the model. Section 5 presents sensitivity experiments to examine the impact of the surrounding mountainous topography. Section 6 discusses a possible maintenance mechanism of the quasi-stationary precipitation system using a trajectory analysis and an evaluation of the low-level thermodynamic environment. Section 7 presents the conclusions.

\section{Synoptic fields and mesoscale features of precipitation in the Okazaki heavy rainfall event}

Figure 1 shows maps of the studied area. Okazaki city is located at the southeastern edge of plain areas surrounding Nagoya city (Fig. 1a). The northwestern part of this plain area is called Nohbi plain, and the southeastern part is called Okazaki plain. Combined, these two plain areas are hereafter referred to as the Nohbi and Okazaki plain areas. The Nohbi and Okazaki plain areas are surrounded by mountains to the west (the Suzuka mountains), north (the Hida and Ryohaku mountains) and east (the Kiso mountains).

Figure 2 shows a time series of 10-minute precipitation at Okazaki city, observed by the Japan Meteorological Agency's Automated Meteorological Data Acquisition System. Heavy rainfall started at 1500 UTC and lasted until 2000 UTC. The accumulated rainfall during this period totaled $261 \mathrm{~mm}$.

Figure 3 shows surface weather charts at 1200 UTC on 27, 28, and 29 August 2008, before and after the Okazaki heavy rainfall event. A nearly stationary synoptic-scale front was located on the Japan-Sea side of the Japanese archipelago. Synoptic-scale high pressure was seen far east from the Japan Islands over the Pacific Ocean, while synoptic-scale low pressure slowly moved southeastward over the ocean, south of Kyushu Island. As will be shown later with model simulation results, in the Tokai area, southeasterly winds from the Pacific Ocean blew into the synopticscale front during this period. These winds supplied warm, moist air from the ocean to the Tokai area during the Okazaki heavy rainfall event.

Figure 4 shows the distributions of observed radar reflectivity for 1300-2100 UTC on 28th in the Tokai area. At 1300 UTC, a line of precipitation (indicated by $\mathrm{S}$ in Fig. 4a) is located about $60 \mathrm{~km}$ northwest of Okazaki city. Another precipitation system (indicated by A) is located on the southeast side of system S. By 1400 UTC, while system S moved southeastward to approach system A, a new system B formed on the southeast side of system A (Fig. 4b). By 1600 UTC, systems $\mathrm{S}, \mathrm{A}$, and $\mathrm{B}$ lined up in a north-south direction 
(a)

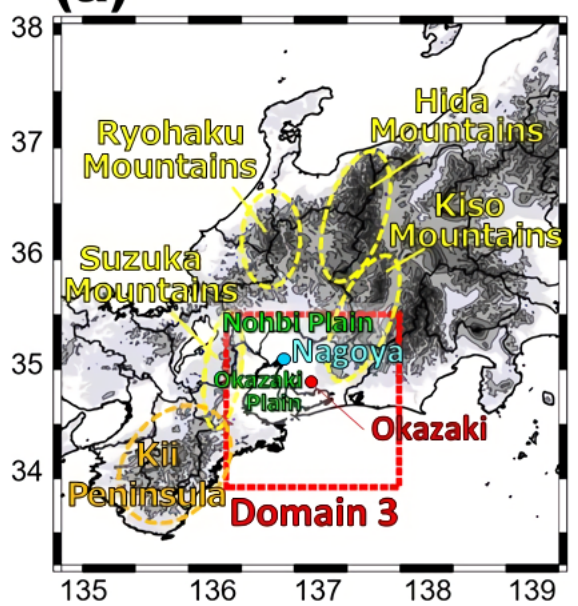

(b)

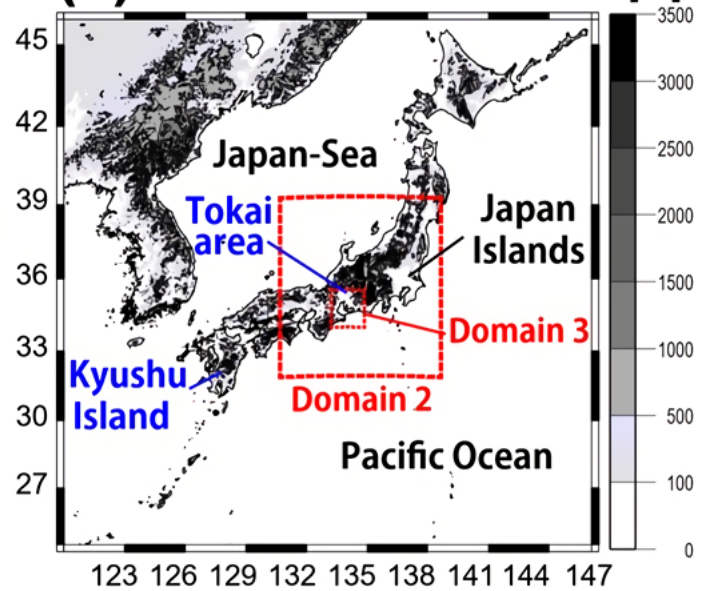

Fig. 1. (a) Map of the Tokai area. The red dotted lines indicate model domain 3. (b) Map of the Japan Islands showing model domain 1 with boxes indicating model domains 2 and 3.

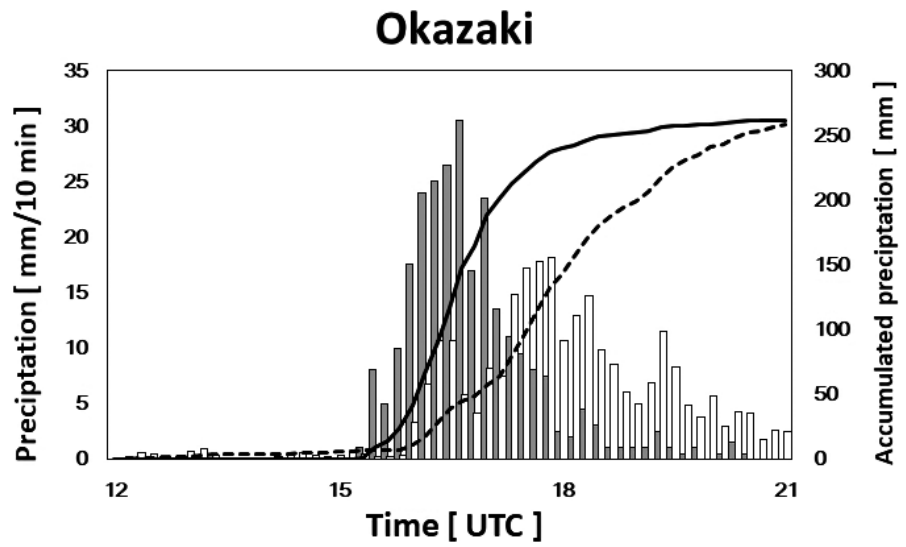

Fig. 2. 10-minute precipitation amount (gray bars show observation, and white bars show simulated results from CTL simulation, respectively) and accumulated precipitation amounts (since 1500 UTC, solid line shows observation, and dotted line shows simulated results from CTL simulation, respectively) for Okazaki city from 1200-2100 UTC on 28 August 2008. The observations were obtained from the Automated Meteorological Data Acquisition System (AMeDAS).

(a) 1200 UTC 27 August(b)1200 UTC 28 August (c)1200 UTC 29 August

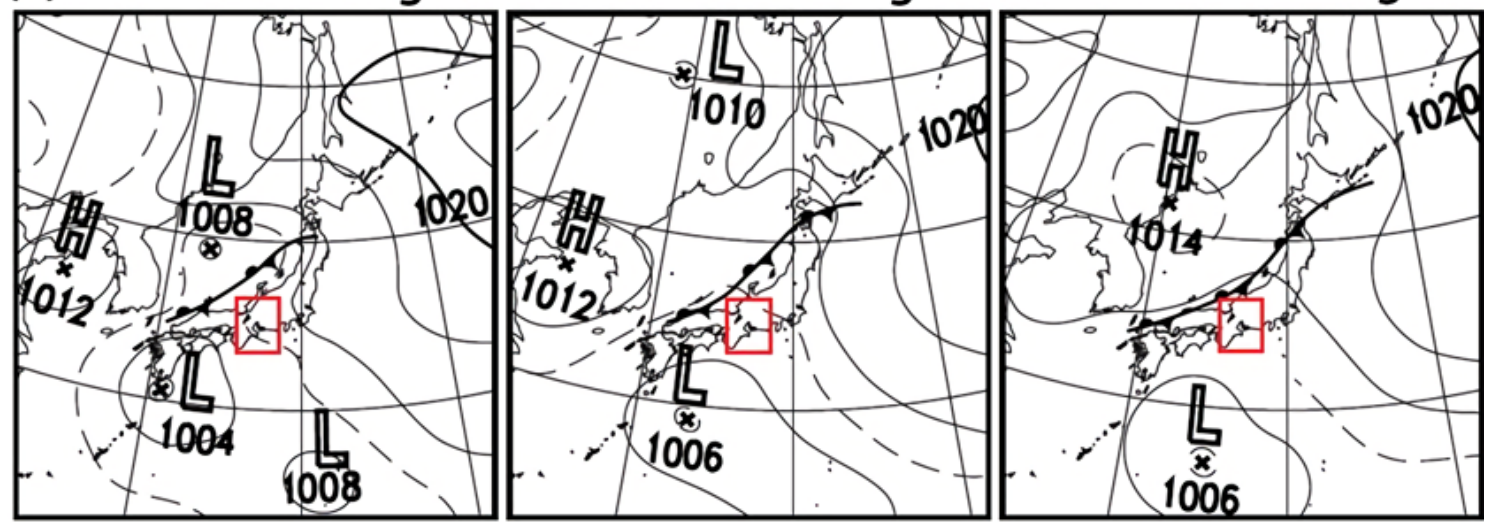

Fig. 3. Surface weather charts (by the Japan Meteorological Agency) at 1200 UTC on (a) 27, (b) 28, and (c) 29 August 2008. Contour interval is $4 \mathrm{hPa}$ (solid lines); dashed contour represents 1006, 1010, and $1014 \mathrm{hPa}$ isobars. Areas enclosed by red lines indicate the Tokai area. 


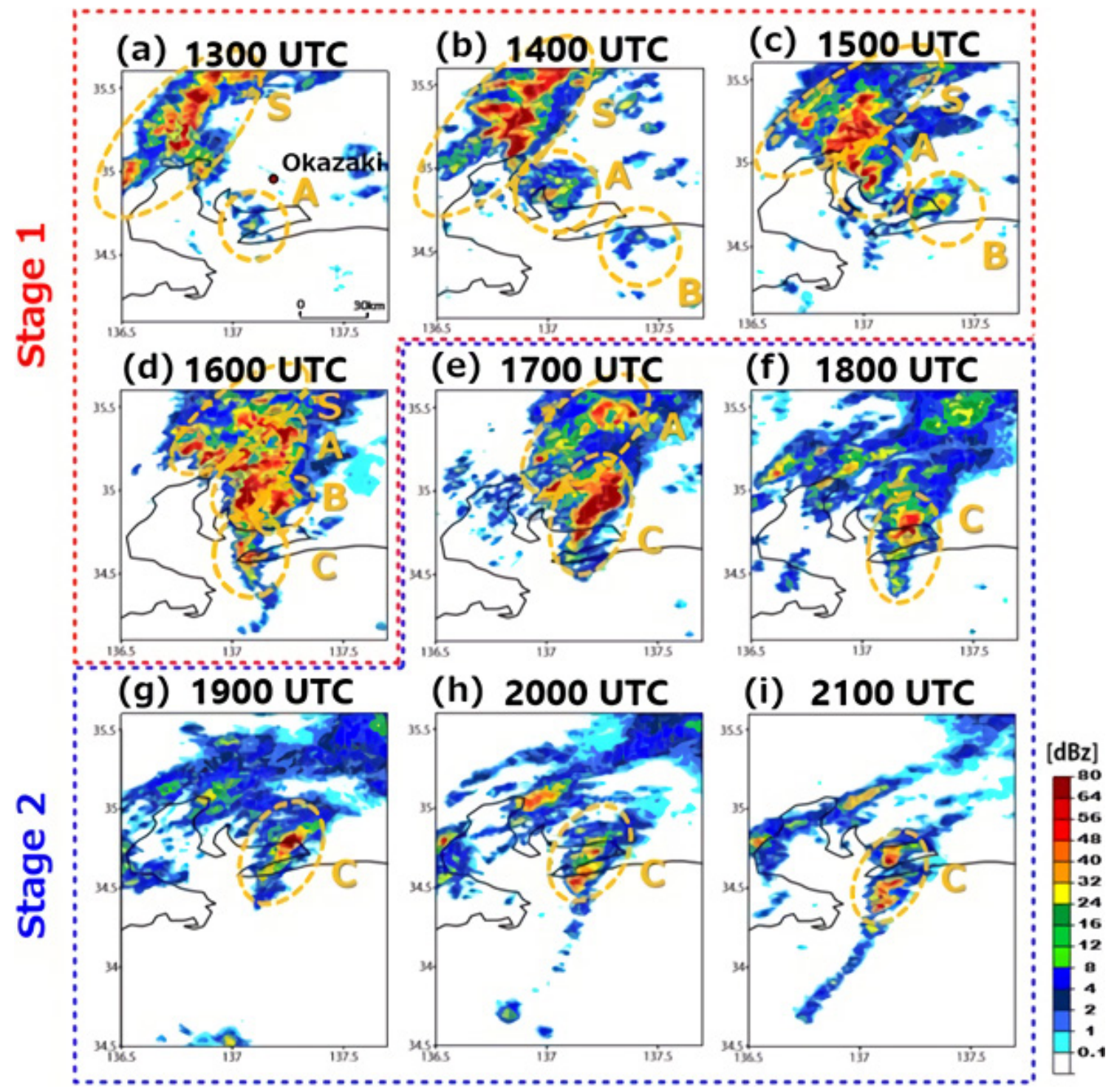

Fig. 4. Radar reflectivity (dBz) observations (by the Japan Meteorological Agency) at (a) 1300, (b) 1400, (c) 1500, (d) 1600 , (e) 1700 , (f) 1800, (g) 1900, (h) 2000, and (i) 2100 UTC on 28 August 2008. A, B, C, and S are mesoscale precipitation systems. The solid lines indicate coastlines.

around Okazaki city. On the south side of the lined systems, a new system formed (indicated by C, Fig. 4d). By 1700 UTC, system S merged with A, while system B merged with C (Fig. 4e). By 1800 UTC, system A dissipated, but system C remained quasistationary around Okazaki city until around 2100 UTC (Figs. 4f-i).

The above sequence can be separated into two stages. In stage 1 , system $\mathrm{S}$ moved southeastward toward system A. Then, together with systems B and
$\mathrm{C}$, these systems lined up in a north-south direction around 1600 UTC. In stage 2, the system C remained quasi-stationary around Okazaki city. The subsequent analysis focuses on this quasi-stationary precipitation system during stage 2 .

\section{Outline of numerical simulation}

We used the Weather Research and Forecasting (WRF) model, Version 3.4.1, to investigate the quasistationary precipitation system around the Okazaki 


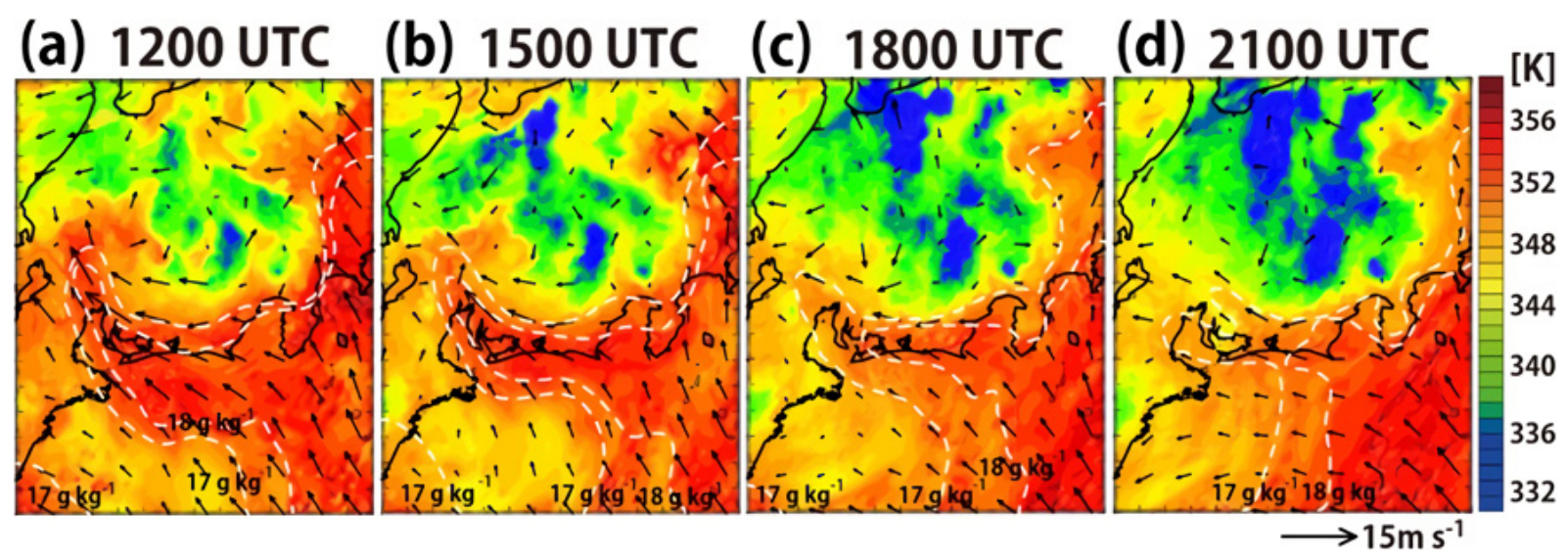

Fig. 5. Simulated horizontal distributions of equivalent potential temperature (color) and winds (arrows) at a height of $500 \mathrm{~m}$ above surface from model domain 2 at (a) 1200, (b) 1500, (c) 1800, and (d) 2100 UTC on 28 August 2008. Dashed white contours represent water vapor mixing ratio $\left(\mathrm{g} \mathrm{kg}^{-1}\right)$. Solid lines indicate coastlines.

area. A horizontal two-way nesting was used with three model domains. The horizontal resolution of model domain 1 was $12.5 \mathrm{~km}$, with 170 (north-south direction) $\times 190$ (west-east direction) grid points (Fig. 1b). Similarly, model domain 2 consisted of $321 \times 321$ grid points at $2.5 \mathrm{~km}$ resolution, and model domain 3 consisted of $351 \times 421$ grid points at $500 \mathrm{~m}$ resolution (Fig. 1a). The vertical coordinate $\eta$ had finer resolutions at lower levels. The top of atmosphere was $100 \mathrm{hPa}$ with 55 vertical layers underneath. The initial and boundary conditions for the WRF model were provided by a 3-hourly output of the Japan Meteorological Agency's operational mesoscale model (Japan Meteorological Agency 2013). The lower boundary condition for sea surface temperature is provided by merging satellite and in situ data Global Daily Sea Surface Temperatures (MGDSST) data (Kurihara et al. 2006). The model topography is based on the United States Geological Survey's Global 30 Arc-Second Elevation (USGS GTOPO30) data. The WRF model simulated for $0000-2100$ UTC on 28 August 2008 for all three model domains. The Thompson microphysics scheme (Thompson et al. 2004), Mlawer longwave radiation scheme (Mlawer et al. 1997), Dudhia shortwave radiation scheme (Dudhia 1989), Noah land-surface model (Chen and Dudhia 2001), and Mellow-Yamada-Janjic Level 2.5 planetary boundary layer scheme (Janjic 2002) are used as physics parameters. The Kain-Fritch convective parameterization scheme (Kain 2004) was additionally used, but only for model domain 1 . Further details of the WRF model are in Skamarock et al. (2008).

\section{Characteristics of the quasi-stationary precipitation system simulated by WRF}

In Fig. 5, the simulation showed that warm, moist air at $500 \mathrm{~m}$ above the surface, with equivalent potential temperature $\left(\theta_{e}\right)$ greater than $355 \mathrm{~K}$ and mixing ratio of water vapor $(q)$ greater than $18 \mathrm{~g} \mathrm{~kg}^{-1}$, was coming ashore to the Tokai area from the southeast or east-southeast between 1200 UTC and 2100 UTC on 28 August 2008. The Okazaki rainfall event occurred at 1500 UTC.

Figure 6 shows the distributions of simulated hourly precipitation amounts and $10 \mathrm{~m}$ surface winds for 1300-2100 UTC in model domain 3. The observed precipitation pattern's general characteristics are well captured. In stage 1, an organized precipitation system moved southeastward to form a band-shaped precipitation system near Okazaki city around 1600 UTC (Figs. 6a-d). In stage 2, the system remained quasistationary around Okazaki city and produced heavy, prolonged precipitation for 1700-2100 UTC (Figs. $6 \mathrm{e}-\mathrm{i})$. The simulated precipitation amount in Okazaki city totaled about $250 \mathrm{~mm}$ by 2100 UTC. However, the simulated peak precipitation time was about one hour later (Fig. 2). Throughout stage 2, easterly and east-southeasterly winds are maintained on the southeastern side of the quasi-stationary system (indicated by thick red arrows in Fig. 6). Northerly winds developed on the western side of the quasi-stationary system and converged with the southeasterly winds to form a low-level convergence line (indicated by red dash lines in Fig. 6) on the south side of the quasi-stationary system. This convergence line is apparent from the 


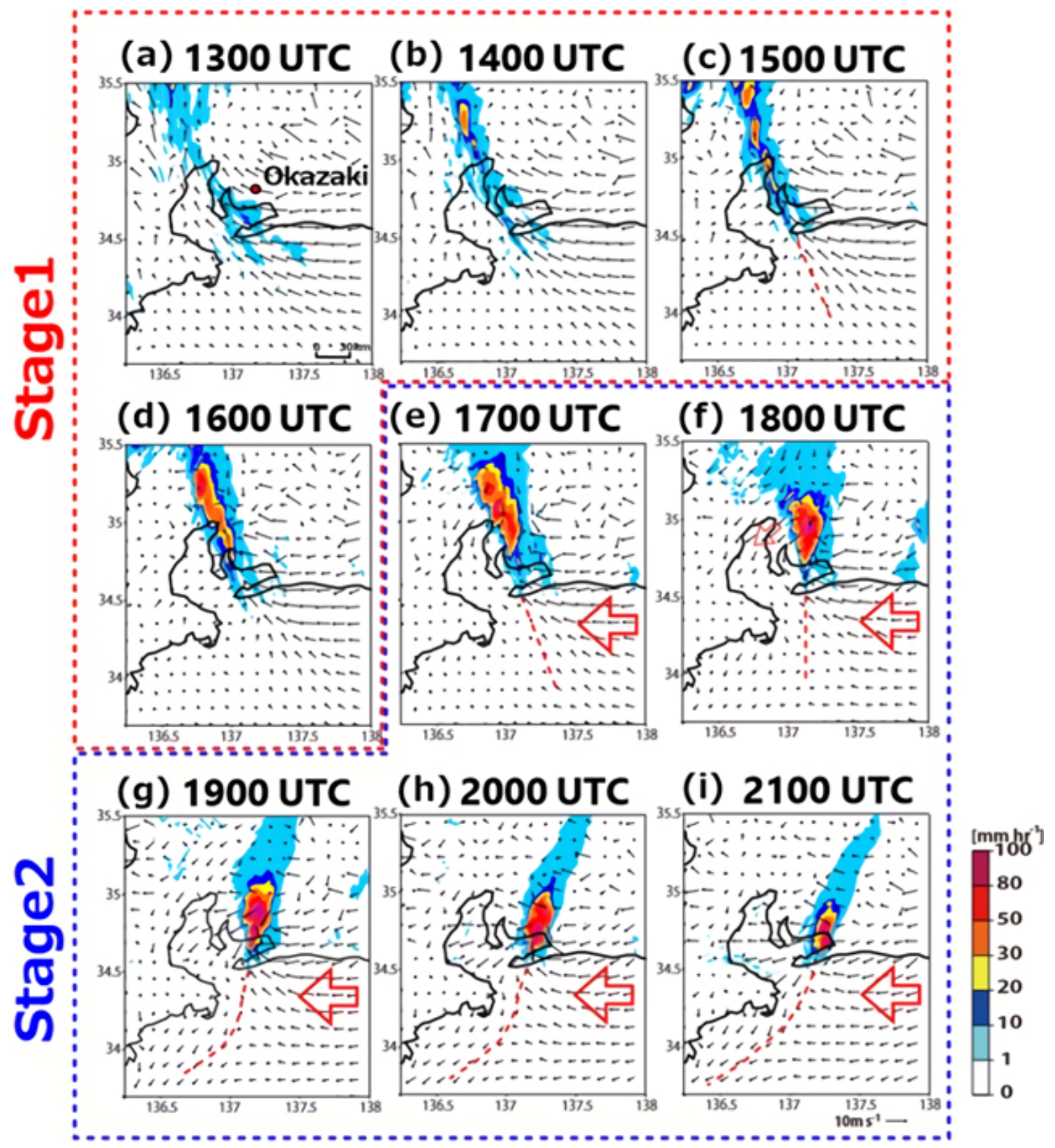

Fig. 6. Simulated horizontal distributions of hourly precipitation $\left(\mathrm{mm} \mathrm{hr}^{-1}\right)$ and surface winds from model domain 3 at (a) 1300, (b) 1400, (c) 1500, (d) 1600, (e) 1700, (f) 1800, (g) 1900, (h) 2000, and (i) 2100 UTC on 28 August 2008. The solid lines indicate coastlines. The red dashed lines indicate convergence zones.

surface to a $500 \mathrm{~m}$ height.

\section{Impact of topography on the quasi-stationary precipitation system}

Okazaki city is located at the southeastern edge of the Nohbi and Okazaki plain areas, with mountains to the west, east and north (Fig. 1a), as described in Section 2. Considering the above-noted Okazaki city geography, the surrounding mountainous topography probably affected the quasi-stationarity of Okazaki rainfall. In particular, the mountains east of Okazaki city may prevent eastward movement of the precipi- 


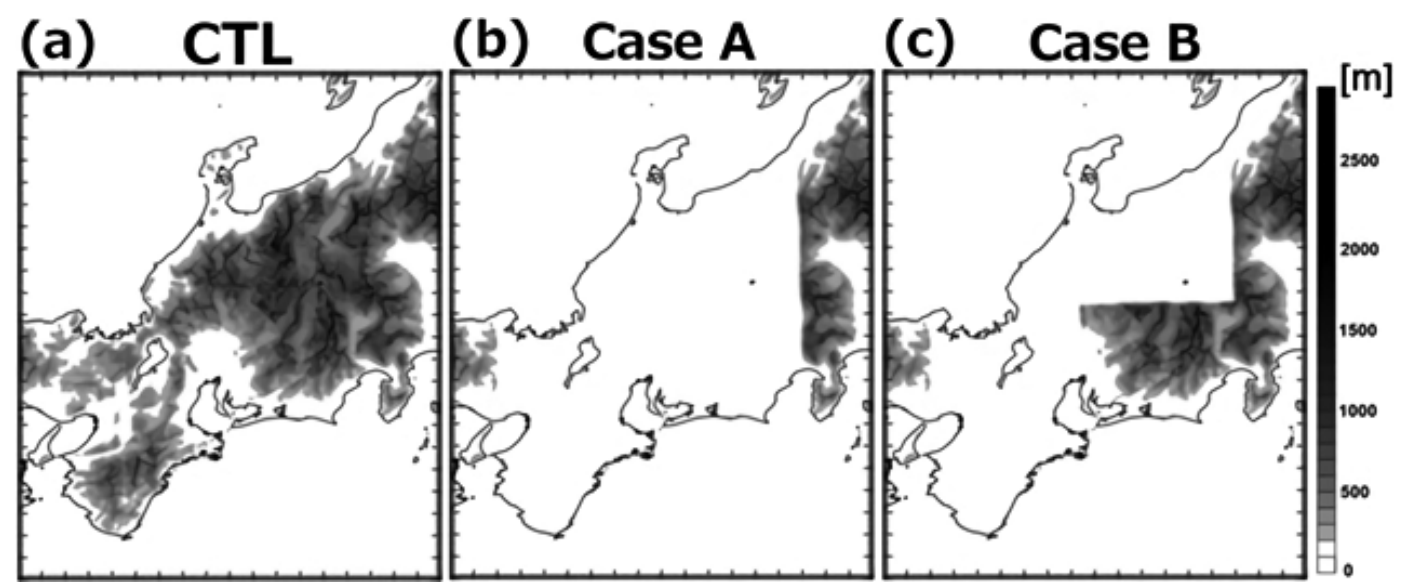

Fig. 7. Model topography used for sensitivity experiments for (a) CTL, (b) Case A, and (c) Case B.

tation system, leading to prolonged quasi-stationarity around Okazaki city.

With the above discussion in mind, the following sensitivity experiments were performed with ideal topography, as shown in Fig. 7, namely:

- Control (CTL); with real topography (Fig. 7a),

- Case A; all mountains within $200 \mathrm{~km}$ from Okazaki city are removed (Fig. 7b),

- Case B; similar to Case A, all mountains within $\sim 200 \mathrm{~km}$ from Okazaki city are removed except for the southeastern quadrant (i.e., only mountains directly east of Okazaki city remain) (Fig. 7c).

The topography modifications start at the model initial time (0000 UTC); therefore, the model atmosphere is considered well-adjusted to the modified topography before the quasi-stationary precipitation system forms. Topography in model grids between the original and the modified portions are smoothed by linearly interpolating over five model grid points. Topography interpolation is applied to all model domains.

Figure 8 shows spatial distributions of the hourly precipitation amounts and surface winds from sensitivity experiments at 1300, 1600, and 1900 UTC. In Case A, a precipitation pattern associated with synoptic-scale front formed during stage 1 (indicated by ovals with dashed lines in Figs. 8b, e). A convergence line extended southward from this precipitation area. MCSs successively formed and moved along the convergence line to form a band-shaped precipitation system (indicated by ovals with solid lines in Figs. 8b, e). These features of the stage 1 precipitation system were similar to those in CTL. However, the stage 1 precipitation system was located about $50 \mathrm{~km}$ east compared to the CTL simulation (Figs. 8d, e). Furthermore, unlike CTL, the precipitation system dissipated by 1900 UTC (Fig. 8h). In contrast, the Case B experiment reproduced the quasi-stationary precipitation from 1600 UTC to 1900 UTC around Okazaki city (Figs. 8f, i). Compared to the CTL case, the spatial distribution of precipitation was slightly different but its intensity was well captured.

We also performed additional sensitivity experiments as described below (topography configurations and horizontal distributions of hourly precipitation at 1900 UTC are shown in Supplement 1).

(1) Elevations of all mountains within $\sim 200 \mathrm{~km}$ east of Okazaki city were halved (Supplement 1a). This experiment produced a band-shaped precipitation system near Okazaki city, but it slowly kept moving eastward (Supplement 1e).

(2) The western half of the all mountains within $\sim 200 \mathrm{~km}$ of Okazaki city were removed (Supplement $1 \mathrm{~b}$ ). Note that this experiment is similar to Case B (Fig. 7c) except the mountains northeast of Okazaki city are present. Similar to Case B, a quasi-stationary precipitation system was produced near Okazaki city (Supplement 1f).

(3) The eastern half of the all mountains within $\sim 200$ $\mathrm{km}$ of Okazaki city were removed (Supplement 1c). No quasi-stationary precipitation system was produced near Okazaki city in this experiment (Supplement 1g).

(4) Mountains over the Kii peninsula were removed (Supplement 1d), producing a quasi-stationary system. However, compared to the CTL case, the intensity was weaker and the orientation of the band-shaped precipitation system was slightly 

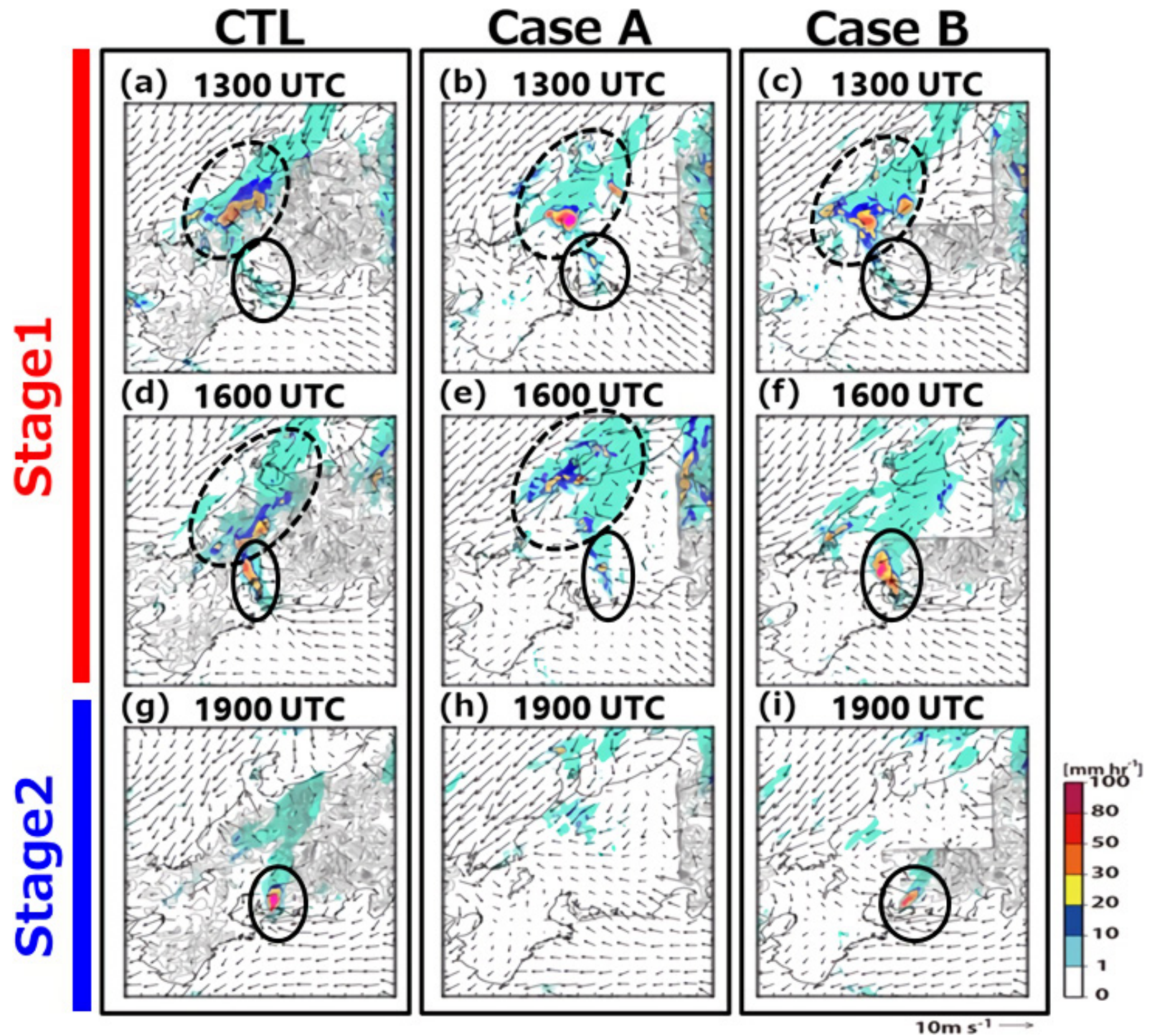

Fig. 8. Simulated horizontal distributions of hourly precipitation $\left(\mathrm{mm} \mathrm{hr}^{-1}\right)$ and surface winds by sensitivity experiments (from model domain 2) at 28 August 2008 at 1300, 1600, and 1900 UTC for (a), (d), (g) CTL, (b), (e), (h), Case A, and (c), (f), (i) Case B. The thin solid line contours indicate topography (drawn at $200 \mathrm{~m}$ interval). The black ovals indicate precipitation systems (see main texts for the details).

rotated clockwise (Supplement $1 \mathrm{~h}$ ).

Therefore, mountains to the east of Okazaki city were essential for the formation and maintenance the quasi-stationary precipitation system during stage 2 .

\section{Discussion}

We discuss a possible mechanism on how the mountains east of Okazaki city contributed to the formation and maintenance of the quasi-stationary precipitation system during stage 2. Figure 9 shows distributions of winds $500 \mathrm{~m}$ above the surface and the average $\theta_{e}$ from the surface to $500 \mathrm{~m}$ height for the CTL, Case A and Case B experiments. In CTL, easterly and southeasterly winds steadily supplied high $\theta_{e}$ air $\left(\theta_{e}>355 \mathrm{~K}\right)$ to Okazaki city for stages 1 and 2 (Figs. 9a, d, g). A similar pattern was observed in Case B, but less intense precipitation was simulated because of the lower $\theta_{e}$ (Figs. 9c, f, i). On the other hand, in Case A, easterly winds from the ocean dissipated by 1600 UTC (Figs. 9e, h). As a result, the high $\theta_{e}$ inflow 


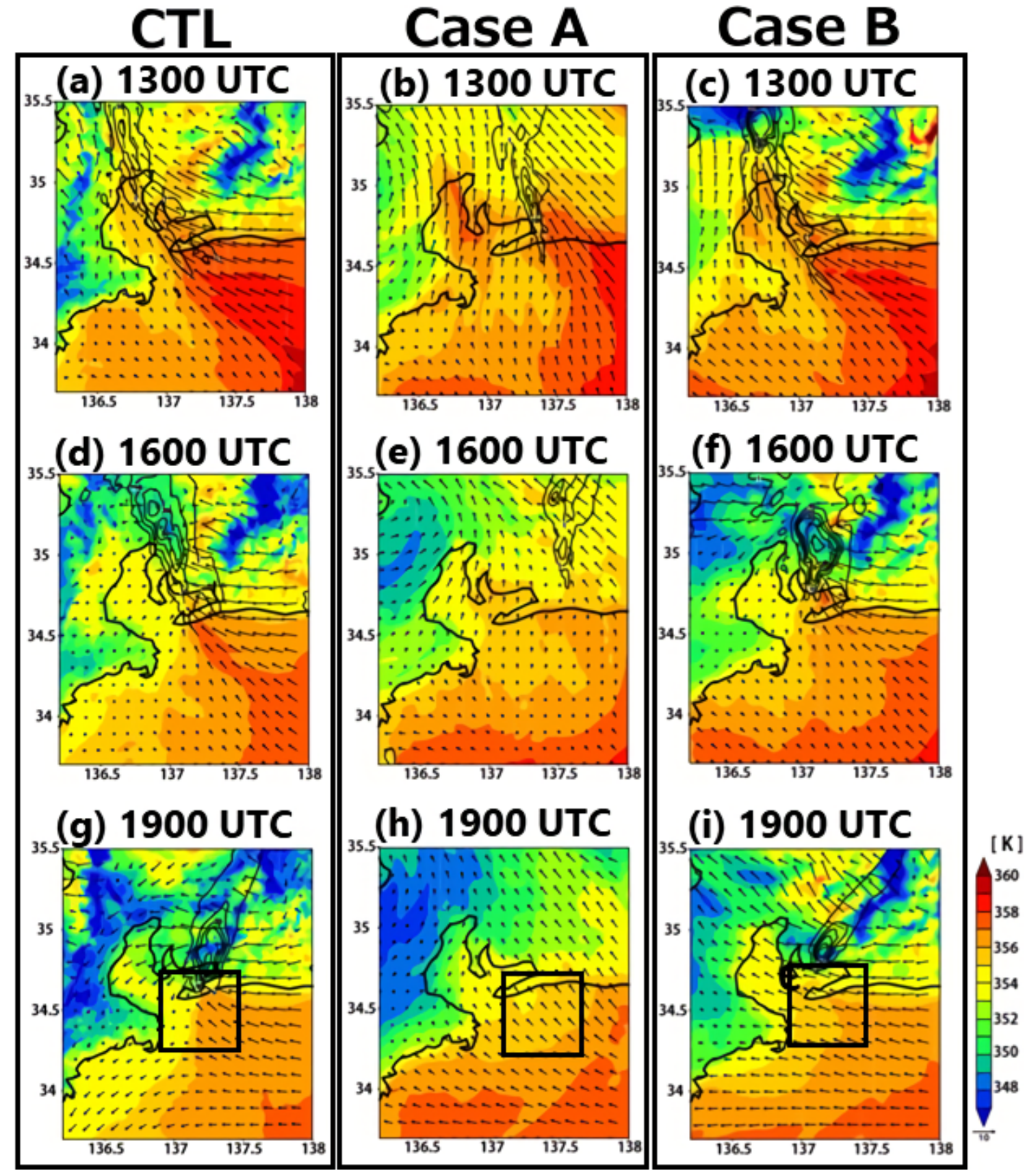

Fig. 9. Same as Fig. 8, but for equivalent potential temperature averaged from the surface to a $500 \mathrm{~m}$ height and winds $500 \mathrm{~m}$ above the surface. The thin solid lines indicate hourly precipitation (contours drawn for 1, 10, 20, 30, 50,80 , and $100 \mathrm{~mm} \mathrm{hr}^{-1}$ ).

during stage 2 was weaker compared to CTL and Case B. Maintenance of the quasi-stationary precipitation system during stage 2 could be associated with easterly and southeasterly winds blowing to Okazaki city, which provides steady inflow of high $\theta_{e}$ to the area.

Figure 10 shows the time series of divergence averaged over the coastal area south of Okazaki city (indicated by black boxes in Figs. 9g, h, i). The CTL 


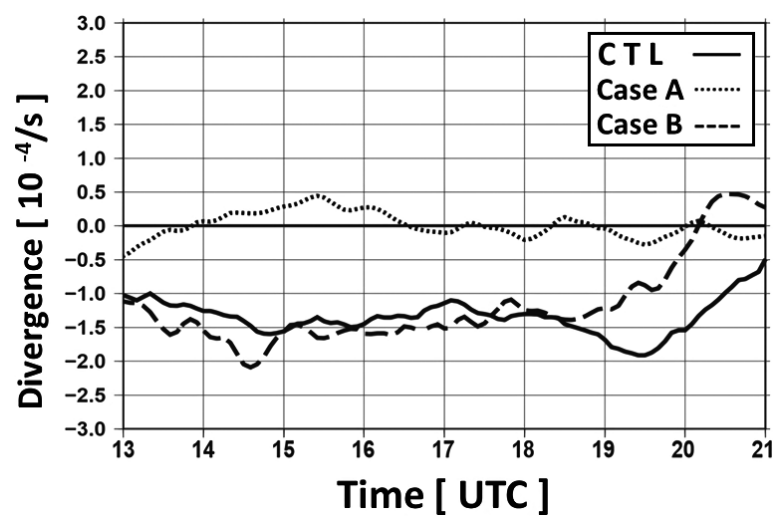

Fig. 10. Time evolutions of low-level divergence (averaged from the surface to $500 \mathrm{~m}$ height over the area enclosed by black boxes in Fig. 9) for CTL, Case A and Case B.

and Case B were associated with sustained low-level convergence. In contrast, for Case A, the low-level horizontal convergence did not occur. Meanwhile, the latent heat flux from the ocean did not change substantially with or without mountains east of Okazaki city (not shown).

To investigate how easterly and southeasterly winds were sustained in CTL and Case B, we performed a forward trajectory analysis (Stoelinga 2009). Parcels were released from the Pacific Ocean southeast of the Tokai area at the initial model time (0000 UTC on 28 August) $250 \mathrm{~m}$ above the surface. Figure 11 shows the representative parcel trajectories for 0000-1900 UTC. In CTL and Case B, the parcels traveled northwestward over the Pacific Ocean and gradually shifted westward as they approached the Tokai area (Figs. $11 \mathrm{a}, \mathrm{c})$. This westward shift was caused in the lowlevel atmosphere with low Froude numbers $(\mathrm{Fr}<0.5)$, restricting the parcels crossing over the mountains east of Okazaki city. Here the Froude number $(\mathrm{Fr}=$ $U_{0} / N h$ ) was estimated using the average wind speed under the height of the mountains $\left(U_{0} \sim 8 \mathrm{~m} \mathrm{~s}^{-1}\right)$, a constant Brunt-Vaisala frequency $\left(N \sim 1.2 \times 10^{-2} \mathrm{~s}^{-1}\right)$, and the mountain height (top height: $h \sim 2500 \mathrm{~m}$ ) (Smolarkiewicz and Rotunno 1989).

However, in Case A, the parcels kept moving northwestward toward the Tokai area and did not reach Okazaki city (Fig. 11b). To qualitatively examine the westward shift of the parcels' movements from the Lagrangian perspective, the magnitudes and directions of the pressure gradient and Coriolis forces were calculated along each parcel trajectory (shown as vectors in Fig. 11). With the presence of mountains to the east of Okazaki city, the pressure gradient force on the parcels was $6.6-11 \times 10^{-4} \mathrm{~m} \mathrm{~s}^{-2}$ (in CTL and Case B), but, without the mountains, the pressure gradient force reduced to $3.7-5.0 \times 10^{-4} \mathrm{~m} \mathrm{~s}^{-2}$ (in Case A). Meanwhile, Coriolis forces on the parcels with and without the mountains were $5.8-7.4 \times 10^{-4} \mathrm{~m} \mathrm{~s}^{-2}$ and $4.0-5.4 \times 10^{-4} \mathrm{~m} \mathrm{~s}^{-2}$, respectively. Therefore, the enhanced pressure gradient force due to the mountains east of Okazaki city was greater than the changes in the Coriolis force. (a)

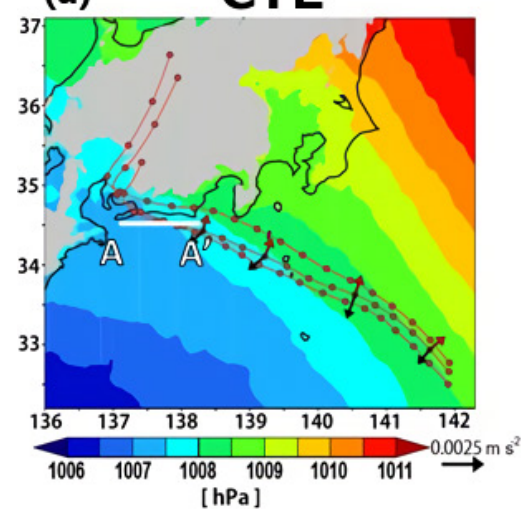

(b) Case A

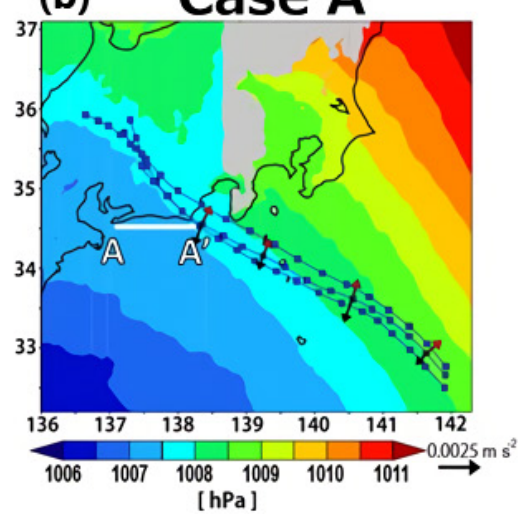

(c) Case B

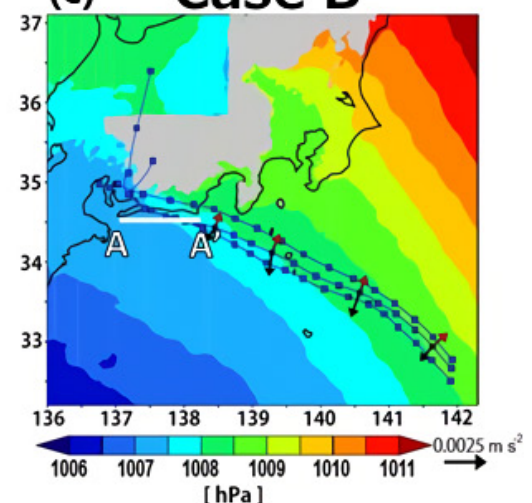

Fig. 11. The forward trajectory analysis results for a pressure level at $250 \mathrm{~m}$ above the surface extrapolated to sea level for (a) CTL, (b) Case A, and (c) Case B. The pressure fields are time averages for 0000-1900 UTC on 28 August. The trajectory dots denote parcel locations for every hour. For panels (a), (b), and (c), the directions and magnitudes of parcel acceleration due to the pressure gradient and Coriolis are shown by black and red vectors, respectively. The gray shading indicates areas with elevations greater than $250 \mathrm{~m}$. 

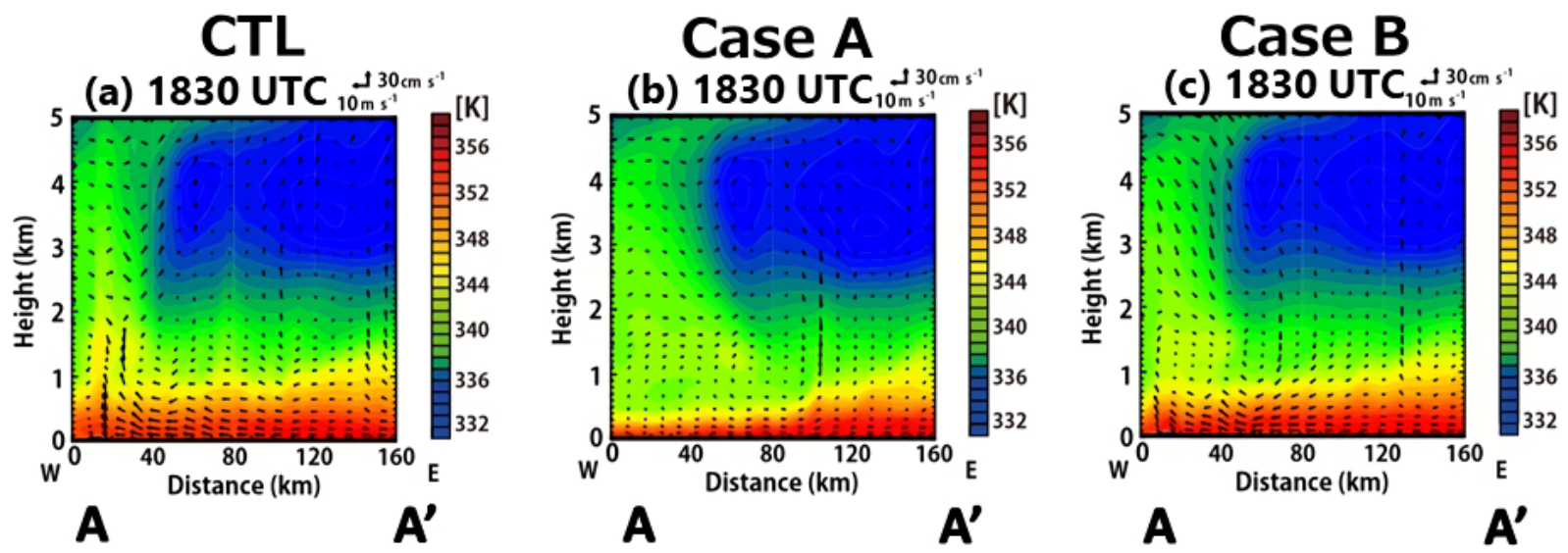

Fig. 12. Vertical cross-sections of equivalent potential temperature and winds along the cross-section at 1830 UTC for (a) CTL, (b) Case A, and (c) Case B. The cross-sections are taken along the white lines in Fig. 11.

Figure 12 shows vertical cross-sections of $\theta_{e}$ and winds for 1830 UTC (a representative time for the quasi-stationary precipitation around Okazaki city). The cross-sections are taken along the white lines in Fig. 11 (denoted by A-A'). In CTL and Case B, a layer of high $\theta_{e}(>345 \mathrm{~K})$ extended from the surface to $800-1000 \mathrm{~m}$ height (Figs. 12a, c). However, in Case A, the layer of high $\theta_{e}$ became relatively thinner in western half of the cross-section because of the eastward shift of high $\theta_{e}$ inflow from the ocean, as illustrated by parcel trajectory shifts shown in Fig. 11b.

The above discussion can be summarized as follows. In the low-level atmosphere with low Froude numbers $(<0.5)$, the enhanced pressure gradient force on the mountain's upstream side worked on the southeasterly flow from the Pacific Ocean to shift westward, resulting in the sustained easterly inflow to Okazaki city. Together with northerly winds blowing from the west of Okazaki city (cf. Fig. 6f), the sustained easterlies formed a low-level convergence south of Okazaki city. The sustained easterlies also provided high $\theta_{e}$ inflow with $\sim 1 \mathrm{~km}$ depth to the convergence zone (Figs. 9, 12) and contributed to prolonged maintenance of the quasi-stationary precipitation system. However, a question remains as to how the northerly winds west of Okazaki city (cf. Fig. 6f) were maintained during stage 2 . This is left for future studies.

\section{Summary}

Most of heavy rainfall events consist of quasistationary precipitation systems. The Okazaki heavy rainfall event, which occurred at midnight on 28 August 2008 around Okazaki city in the central part of the Japan Islands, was caused by a quasi-stationary, band-shaped precipitation system. The Okazaki heavy rainfall event started around 1500 UTC and lasted until around 2100 UTC. This event can be divided into two stages. In stage 1 (1300-1600 UTC), a bandshaped precipitation system moved southeastward to reach Okazaki city. In stage 2 (1700-2100 UTC), the band-shaped precipitation system merged with newly formed MCSs around Okazaki city and became quasi-stationary. The development of stage 1 precipitation was previously described by Shinoda et al. (2009). The present study examined the quasi-stationary precipitation system in stage 2, with a focus on the impact of surrounding mountainous topography.

To examine the mountainous topography's effect on the quasi-stationary precipitation system, a series of numerical simulations were performed using the WRF model. The control simulation reproduced the observed precipitation pattern of the quasi-stationary precipitation system during stage 2 . Analysis of the simulated low-level equivalent potential temperature $\left(\theta_{e}\right)$ and surface winds showed that the quasi-stationary precipitation system was sustained by low-level high $\theta_{e}$ inflow from the east. Next, we examined the surrounding mountainous topography's effect on the quasi-stationary precipitation system. The results showed that, when all mountains within $\sim 200 \mathrm{~km}$ from Okazaki city were removed, no supply of high $\theta_{e}$ was maintained and thus the precipitation system dissipated in stage 2. However, experiments with mountains east of Okazaki city produced the quasistationary precipitation system even when mountains west of Okazaki city were removed. An additional 


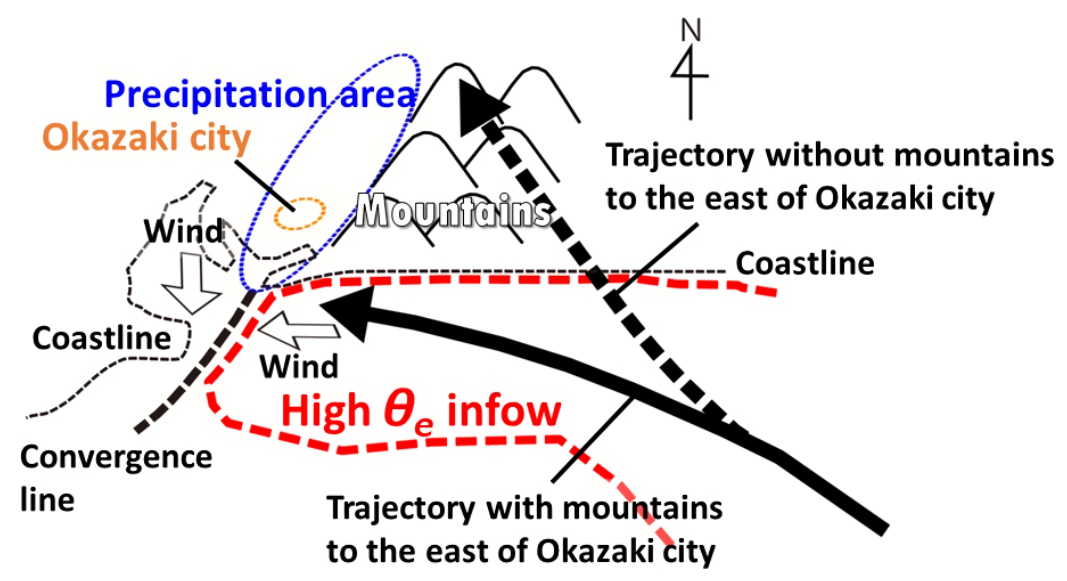

Fig. 13. A schematic illustration of the quasi-stationary precipitation system described in the present study.

experiment with the eastside mountains only half as high produced weaker precipitation intensity and less stationarity. These results indicate that the key topography for maintaining the quasi-stationary precipitation system was the mountains east of Okazaki city.

Figure 13 summarizes the factors contributing to the quasi-stationary precipitation system formed in this study. The sensitivity experiment results indicated that the quasi-stationary precipitation system was maintained because of the mountains east of Okazaki city in the following manner:

(1) Southeasterly winds from the ocean shifted east due to an enhanced pressure gradient associated with the mountains east of Okazaki city.

(2) The sustained easterlies continuously supplied warm, moist air to Okazaki city and formed a low-level convergence, restricting the eastward movement of the precipitation system.

Some issues remain regarding the formation of the stage 1 precipitation system. In our sensitivity experiments, a mesoscale, band-shaped precipitation system formed during stage 1 with or without mountains east of Okazaki city (Fig. 8). However, without mountains east of Okazaki city, the stage 1 precipitation system formed $50 \mathrm{~km}$ east of the control case. The intensity was also weaker compared to the control case. These results indicate that both the location and intensity of the stage 1 precipitation system are also sensitive to topography. Previous studies showed that topography can affect precipitation intensity (Suzuki et al. 2008; Kurihara et al. 2009; Nielsen et al. 2016; Tsuguti and Seino 2017; Meteorological Research Institute 2017). Meanwhile, a case study done by Kato and Goda (2001) on a stationary, band-shaped precipitation system in Niigata (the 4 August 1998 heavy rainfall case) showed little impact from the local topography. Thus, influence of local topography on heavy rainfall events varies by cases. Further investigations are necessary on why and how some heavy rainfall events are affected by local topography.

\section{Supplements}

Supplement 1. Topographical maps (panels in top row), and simulated horizontal distributions of hourly precipitation $\left(\mathrm{mm} \mathrm{hr}^{-1}\right)$ and surface winds at 1900 UTC on 28 August 2008 (panels in bottom row) for (a) and (e) experiment when elevations of all mountains within $\sim 200 \mathrm{~km}$ east of Okazaki city are halved, (b) and (f) experiment with western half of all mountains within $\sim 200 \mathrm{~km}$ of Okazaki city are removed, (c) and (g) experiment with eastern half of the all mountains within $\sim 200 \mathrm{~km}$ of Okazaki city are removed, (d) and (h) experiment without the mountains over the Kii peninsula. Thin solid line contours in the bottom row panels indicate topography (drawn at $200 \mathrm{~m}$ interval).

\section{Acknowledgments}

We thank reviewers and Dr. T. Kato, the Japan Meteorological Agency, for their helpful comments, which improved the original manuscript. The operational radar dataset was provided by the Japan Meteorological Business Support center. The present study was supported in part through the Journal Submission Financial Aid Program, funded by the Graduate Course in Environment Systems, Graduate School of Geoenvironmental Science, Rissho University. 


\section{References}

Bluestein, H. B., and M. H. Jain, 1985: Formation of mesoscale lines of pirecipitation: Severe squall lines in Oklahoma during the spring. J. Atmos. Sci., 42, 17111732.

Chen, F., and J. Dudhia, 2001: Coupling an advanced land surface-hydrology model with the Penn State-NCAR MM5 modeling system. Part I: Model implementation and sensitivity. Mon. Wea. Rev., 129, 569-585.

Dudhia, J., 1989: Numerical study of convection observed during the winter monsoon experiment using a mesoscale two-dimensional model. J. Atmos. Sci., 46, 3077-3107.

Houze, R., Jr., 1993: Cloud Dynamics. Academic Press, 573 pp.

Janjić, Z. I., 2002: Nonsingular implementation of the Mellor-Yamada level 2.5 scheme in the NCEP meso model. National Centers for Environmental Prediction Office Note, No. 437, 61 pp.

Japan Meteorological Agency, 2013: Outline of the operational numerical weather prediction at the Japan Meteorological Agency, March 2013. Appendix to WMO Technical Progress Report on the Global DataProcessing and Forecasting System and Numerical Weather Prediction. [Available at http://www.jma.go. jp/jma/jma-eng/jma-center/nwp/outline2013-nwp/ index.htm.]

Kain, J. S., 2004: The Kain-Fritsch convective parameterization: An update. J. Appl. Meteor., 43, 170-181.

Kanada, S., H. Minda, B. Geng, and T. Takeda, 2000: Rainfall enhancement of band-shaped convective cloud system in the downwind side of an isolated island. $J$. Meteor. Soc. Japan, 78, 47-67.

Kato, T., 1998: Numerical simulation of the band-shaped torrential rain observed over southern Kyushu, Japan on 1 August 1993. J. Meteor. Soc. Japan, 76, 97-128.

Kato, T., and H. Goda, 2001: Formation and maintenance processes of a stationary band-shaped heavy rainfall observed in Niigata on 4 August 1998. J. Meteor. Soc. Japan, 79, 899-924.

Kurihara, Y., T. Sakurai, and T. Kuragano, 2006: Global daily sea surface temperature analysis using data from satellite microwave radiometer, satellite infrared radiometer and in-situ observations. Weather Serv. Bull., 73, s1-s18 (in Japanese).

Kurihara, K., T. Kanamori, and H. Seko, 2009: Band-shaped precipitation system observed in Hiroshima on 18 July 2003: Airflow structure and the effects of terrain and middle-level dry air analysed by JMANHM. Tenki, 56, 613-626 (in Japanese).

Lin, Y.-L., 2007: Mesoscale Dynamics. Cambridge Univ. Press, 630 pp.

Meteorological Research Institute, 2017: About the occurrence factors of heavy rainfall in Fukuoka prefecture and Oita prefecture on July 5-6, 2017. Press release, 8 pp (in Japanese). [Available at https:/www.jma.go.jp/ $\mathrm{jma} /$ press/1707/14b/press_20170705-06_fukuokaoita_heavyrainfall.pdf.]

Mlawer, E. J., S. J. Taubman, P. D. Brown, M. J. Iacono, and S. A. Clough, 1997: Radiative transfer for inhomogeneous atmospheres: RRTM, a validated correlated-k model for the longwave. J. Geophys. Res., 102, 16663-16682.

Morotomi, K., T. Shinoda, Y. Shusse, T. Kouketsu, T. Ohigashi, K. Tsuboki, H. Uyeda, and I. Tamagawa, 2012: Maintenance mechanisms of a precipitation band formed along the Ibuki-Suzuka Mountains on September 2-3, 2008. J. Meteor. Soc. Japan, 90, 737753.

Nielsen, E. R., R. S. Schumacher, and A. M. Keclik, 2016: The effect of the Balcones Escarpment on three cases of extreme precipitation in central Texas. Mon. Wea. Rev., 144, 119-138.

Ninomiya, K., 2011: Features of meso-scale precipitation systems of intense Hida river rainfalls on August 17, 1968. Tenki, 58, 305-316 (in Japanese).

Ogura, Y., 1991: Analysis of mechanism of intense precipitation. Tenki, 38, 276-288 (in Japanese).

Ogura, Y., 2015: Weather in Japan: Its Diversity and Mechanism. University of Tokyo Press, 403 pp (in Japanese).

Ogura, Y., T. Asai, and K. Dohi, 1985: A case study of a heavy precipitation event along the Baiu front in northern Kyushu, 23 July 1982: Nagasaki heavy rainfall. J. Meteor. Soc. Japan, 63, 883-900.

Ogura, Y., R. Kumabe, and S. Nishimura, 2011: An analysis of weather systems in "the heavy precipitation period in late August 2008", with an emphasis on organization of mesoscale convective systems. Tenki, 58, 201-217 (in Japanese).

Seko, H., 2001: Study of the shapes and maintenance mechanisms of meso- $\beta$ scale line-shaped precipitation systems in the middle-latitudes. Doctoral thesis, University of Tokyo, $136 \mathrm{pp}$ (in Japanese).

Shinoda, T., M. Kato, Y. Shusse, M. Nomura, M. Oue, T. Kouketsu, K. Tsuboki, and H. Uyeda, 2009: Structure of a precipitation system developed around Aichi Prefecture, Japan, on August 28-29, 2008. International Conference on Mesoscale Convective Systems (MCSs) and High-Impact Weather/Climate in East Asia (ICMCS-VII), Seoul, Korea, 47-55.

Skamarock, W. C., J. B. Klemp, J. Dudhia, D. O. Gill, D. M. Barker, M. G. Duda, X.-Y. Huang, W. Wang, and J. G. Powers, 2008: A description of the advanced research WRF version 3. NCAR Technical Note, NCAR/TN475+STR, $113 \mathrm{pp}$.

Smolarkiewicz, P. K., and R. Rotunno, 1989: Low Froude number flow past three-dimensional obstacles. Part I: Baroclinically generated lee vortices. J. Atmos. Sci., 46, 1154-1164.

Stoelinga, M. T., 2009: A users' guide to RIP version 4: 
A program for visualizing mesoscale model output. Technical Note, University of Washington, $81 \mathrm{pp}$.

Suzuki, Y., T. Anbe, Y. Usui, and M. Hasebe, 2008: Numerical experiment on the relationship between the form of topography and the fields of precipitation and wind velocity in linear convective systems. Proc. Hydraul. Eng., 52, 337-342 (in Japanese).

Thompson, G., R. M. Rasmussen, and K. Manning, 2004: Explicit forecasts of winter precipitation using an improved bulk microphysics scheme. Part I: Description and sensitivity analysis. Mon. Wea. Rev., 132, 519542.

Tsuguti, H., and N. Seino 2017: About the characteristics of "heavy rainfall in Fukuoka and Oita prefecture on July 5-6, 2017." Proceedings of the Autumn Conference of Japan Meteorological Society, 171-171 (in Japanese). Watanabe, H., 2008: Structure of the heavy rainfall system in Mie prefecture (29th September 2004). Tenki, 55, 807-812 (in Japanese).

Yoshizaki, M., T. Kato, Y. Tanaka, H. Takayama, Y. Shoji, H. Seko, K. Arao, K. Manabe, and Members of X-BAIU98 Observation, 2000: Analytical and numerical study of the 26 June 1998 orographic rainband observed in western Kyushu, Japan. J. Meteor. Soc. Japan, 78, 835-856. 